\title{
PENGEMBANGAN PERANGKAT PEMBELAJARAN MODEL QUANTUM LEARNING UNTUK MENINGKATKAN HASIL BELAJAR FISIKA PESERTA DIDIK
}

\author{
Tesya Aprilia1), Sutrio'1), Hairunisyah Sahidu') \\ 1)Program Studi Pendidikan Fisika, FKIP, Universitas Mataram, Mataram, NTB, Indonesia \\ Corresponding author :Tesya Aprilia \\ E-mail : tesyaaprilia74@gmail.com
}

\section{Diterima 23 November 2020, Direvisi 01 Februari 2021, Disetujui 03 Februari 2021}

\begin{abstract}
ABSTRAK
Penelitian pengembangan ini bertujuan untuk menghasilkan produk berupa perangkat pembelajaran model quantum learning untuk meningkatkan hasil belajar fisika peserta didik. Desain penelitian yang digunakan adalah model 4D yang terdiri dari Define, Design, Develop, dan Disseminate. Produk yang dikembangkan berupa silabus, rencana pelaksanaan pembelajaran, lembar kerja peserta didik, instrumen tes berupa soal dan video pembelajaran. Pengumpulan data menggunakan lembar validasi dan soal pilihan ganda. Validitas produk dianalisis dengan menentukan nilai Content Validity Index (CVI) dan reliabilitas produk ditentukan berdasarkan nilai Percentage Agreement (PA). Peningkatan hasil belajar fisika dianalisis dengan menentukan standar gain dari hasil pretest dan posttest. Silabus, rencana pelaksanaan pembelajaran, lembar kerja peserta didik, soal tes dan video pembelajaran memiliki nilai CVI lebih besar dari nol sehingga kualitasnya masuk dalam kategori sangat baik. Silabus, rencana pelaksanaan pembelajaran, lembar kerja peserta didik, soal tes dan video pembelajaran memiliki nilai Percentage Agreement (PA)di atas $75 \%$, ini menunjukkan bahwa keseluruhan aspek yang dinilai termasuk dalam kategori reliabel. Hasil belajar fisika mengalami peningkatan dengan nilai gain sebesar 0,114. Berdasarkan hasil tersebut dapat disimpulkan bahwa perangkat pembelajaran yang dikembangkan layak dan efektif digunakan untuk meningkatkan hasil belajar fisika peserta didik.
\end{abstract}

Kata kunci: perangkat pembelajaran; model quantum learning; hasil belajar fisika.

\begin{abstract}
This development research aims to produce a product in the form of a quantum learning model to improve students' physics learning outcomes. The research design used was a 4D model consisting of Define, Design, Develop, and Disseminate. Products developed in the form of a syllabus, lesson plans, student worksheets, test instruments in the form of questions and learning videos. Data collection using validation sheets and multiple choice questions. Product validity is analyzed by determining the value of the Content Validity Index $(\mathrm{CVI})$ and product reliability is determined based on the value of the Percentage Agreement (PA). The improvement of physics learning outcomes was analyzed by determining the standard gain from the pretest and posttest results. The syllabus, lesson plans, student worksheets, test questions and learning videos have a CVI value greater than zero so that the quality is in the very good category. The syllabus, lesson plans, student worksheets, test questions and learning videos have a Percentage Agreement (PA) value above $75 \%$, this indicates that all the aspects assessed fall into the reliable category. Physics learning outcomes have increased with a gain value of 0.114. Based on these results it can be concluded that the learning tools developed are feasible and effective to use to improve students' physics learning outcomes.
\end{abstract}

Keywords: learning devices; quantum learning models; physics learning outcomes.

\section{PENDAHULUAN}

Pendidikan dilaksanakan untuk meningkatkan kualitas sumber daya manusia dengan membentuk peserta didik yang berkompeten dalam segala aspek kehidupan. Pendidikan adalah usaha sadar dan terencana untuk mewujudkan suasana belajar dan proses pembelajaran agar peserta didik secara aktif mengembangkan potensi dirinya untuk memiliki kekuatan spiritual keagamaan, pengendalian diri, kepribadian, kecerdasan, akhlak mulia, serta keterampilan yang diperlukan dirinya, masyarakat, bangsa dan Negara (UndangUndang No. 20 Tahun 2003 tentang Sistem pendidikan Nasional Pasal 1). Pentingnya pendidikan bagi Indonesia terlihat pada tujuan pendidikan nasional yang ingin dicapai. Menurut Undang-Undang Nomor 20 Tahun 
2003 tentang Sistem Pendidikan Nasional, Pasal 3, tujuan Pendidikan Nasional adalah mengembangkan potensi peserta didik agar menjadi manusia yang beriman dan bertakwa kepada Tuhan Yang Maha Esa, berakhlak mulia, sehat, berilmu, cakap, kreatif, mandiri, dan menjadi warga negara yang demokratis dan bertanggung jawab (Undang-Undang No. 20 tahun 2003 tentang Sinstem Pendidikan Nasional).

Tujuan pendidikan nasional dapat dicapai melalui kegiatan pembelajaran di sekolah, salah satunya pembelajaran fisika. Kegiatan pembelajaran memiliki tujuan pada setiap materi pokok yang menjadi acuan penilaian atau evaluasi hasil belajar untuk mengetahui sejauh mana ketercapaiannya. Hasil belajar merupakan proses perubahan kemampuan intelektual (kognitif), kemampuan minat atau emosi (afektif) dan kemampuan motorik halus dan kasar (psikomotor) pada peserta didik (Afandi et al., 2013). Menurut (Rosa, 2015) ranah kognitif merupakan kemampuan atau pengetahuan yang dimiliki peserta didik setelah mengikuti proses pembelajaran, kemudian ranah afektif merupakan kemampuan dalam sikap atau respons yang diberikan peserta didik pada proses pembelajaran, sedangkan ranah psikomotor merupakan sikap yang berkenaan dengan keterampilan atau skill yang dimiliki peserta didik dalam mengaplikasikan materi yang telah didapat.

Gunawan \& Paluti, (2017) menyebutkan bahwa revisi dilakukan terhadap Taksonomi Bloom, yakni perubahan dari kata benda (dalam Taksonomi Bloom) menjadi kata kerja (dalam taksonomi revisi). Perubahan ini dibuat agar sesuai dengan tujuan-tujuan pendidikan. Tujuan-tujuan pendidikan mengindikasikan bahwa peserta didik akan dapat melakukan sesuatu (kata kerja) dengan sesuatu (kata benda). Revisi dilakukan oleh Kratwohl dan Anderson, taksonomi menjadi: (1) mengingat (remember); (2) memahami (understand); (3) mengaplikasikan (apply); (4) menganalisis (analyze); (5) mengevaluasi (evaluate); dan (6) mencipta (create).

Berdasarkan hasil observasi yang telah dilakukan di SMAN 2 Mataram, peserta didik masih kurang aktif dalam pembelajaran, terlihat dari kurangnya kesiapan untuk menerima materi yang akan diajarkan, peserta didik kurang mau berdiskusi dalam memecahkan soal, dan kurangnya inisiatif untuk mencatat materi yang diajarkan. Guru masih kurang dalam memberikan stimulus dan memancing peserta didik untuk mencari sendiri persamaan-persamaan yang akan digunakan dalam memecahkan masalah fisika yang diberikan. Guru langsung memberitahu peserta didik persamaan-persamaan yang belum dipahami secara konsep oleh peserta didik. Hal ini relevan dengan hasil wawancara dengan peserta didik bahwa pelajaran fisika masih terbilang sulit terutama dalam menentukan persamaan yang akan digunakan dalam memecahkan persoalan fisika. Selain itu, peserta didik masih belum mengetahui manfaat dari materi fisika yang diajarkan sehingga ini diduga menjadi penyebab dari sulitnya memahami teori fisika.

Pembelajaran jarak jauh selama pandemi covid-19 menambah permasalahan dalam pelaksanaan pendidikan, khususnya dalam pembelajaran fisika. Peserta didik merasa jenuh karena tidak bisa berinteraksi langsung dengan guru maupun temannya. Selain itu, keterbatasan kuota dan jaringan menyebabkan beberapa peserta didik kesulitan dalam memahami materi yang diajarkan. Hal ini senada dengan hasil wawancara salah satu guru fisika di SMAN 2 Mataram yang mengatakan bahwa guru bersangkutan mengalami beberapa kendala dalam pengajaran, di antaranya yaitu masalah gangguan jaringan ketika berlangsungnya pengajaran. Guru biasanya menggunakan aplikasi zoom, namun waktu yang disediakan terbatas. Metode yang digunakan dalam pengajaran daring adalah metode ceramah yang diperkuat dengan pemberian materi melalui whatsapp. Meskipun demikian, guru masih sulit memonitor peserta didik dalam mempelajari materi yang diberikan. Beberapa masalah di atas menjadi penyebab hasil belajar peserta didik jauh lebih rendah jika dibandingkan dengan pembelajaran secara luring. Hal mengindikasikan bahwa pembelajaran bermakna sulit dicapai dalam pembelajaran daring.

Menurut (Kosasih \& Sumarna, 2013), pembelajaran bermakna terjadi bila peserta didik mencoba menghubungkan fenomena baru ke dalam struktur pengetahuan mereka. Artinya, bahan pelajaran itu harus cocok dengan kemampuan peserta didik dan harus relevan dengan struktur kognitif yang dimiliki peserta didik. Pembelajaran bermakna dapat dicapai dengan cara guru menerapkan suatu alternatif model pembelajaran yang menekankan pada kebermaknaan pembelajaran, adapun solusi yang ditawarkan yaitu dengan menerapkan Model Quantum Learning. (Kosasih \& Sumarna, 2013) juga menyebutkan bahwa model ini sangat menekankan pada kebermaknaan dan kebermutuan proses pembelajaran. Pembelajaran Quantum merupakan kiat, petunjuk, strategi, dan seluruh proses belajar 
yang dapat mempertajam pemahaman dan daya ingat, serta membuat belajar sebagai suatu proses yang menyenangkan dan bermanfaat.

Pemilihan model quantum learning dikarenakan prinsip, langkah-langkah dan tujuan dari model ini sangat cocok untuk mengupayakan pembelajaran bermakna dan diduga membawa pengaruh pada perilaku kognitif, afektif dan psikomotor peserta didik. Apersepsi yang ditumbuhkan pada kegiatan awal pembelajaran dengan menekankan manfaat dalam kehidupan dari materi yang akan diajarkan, mampu memberikan stimulus untuk membangun sendiri struktur kognitif peserta didik. Tingginya frekuensi interaksi antara peserta didik dengan guru maupun dengan peserta didik lain mampu menambah rasa kebersamaan. Selain itu, pengalaman langsung yang dialami peserta didik ketika belajar mampu mengasah motoriknya. Hal ini sesuai dengan penelitian yang telah dilakukan oleh (Hidayana \& Juliani, 2014), bahwa dalam model pembelajaran quantum teaching siswa terlihat aktif daripada menggunakan pembelajaran langsung. Penggunaan model ini dapat meningkatkan hasil belajar dan aktivitas peserta didik.

Penelitian ini didukung oleh penelitian yang sebelumnya dilakukan oleh (Solikin \& Abdullah, 2014), pengajaran dengan menggunakan model quantum berpengaruh positif terhadap hasil belajar peserta didik pada pokok bahasan hukum Newton di kelas X SMA Wahid Hasyim 4 Sidoarjo. Penelitian juga telah dilakukan oleh (Doyan, 2015) dengan hasil yang menunjukkan bahwa mahasiswa yang diajar menggunakan model pembelajaran kuantum memberikan prestasi belajar yang lebih tinggi dibanding dengan mahasiswa yang diajar menggunakan model pembelajaran konvensional.

Penelitian yang relevan dengan penelitian ini antara lain penelitian pengembangan yang dilakukan oleh (Rusyadi et al., 2013) yang berjudul "Pengembangan Perangkat Pembelajaran Quantum Teaching pada Materi Ajar Elastisitas". Hasil temuan disimpulkan bahwa pembelajaran quantum teaching efektif meningkatkan hasil belajar siswa pada materi ajar elastisitas. Penelitian lain yang relevan yaitu penelitian oleh (Ningrum et al., n.d.) yang berjudul "Pengembangan Bahan Ajar Berupa Modul Berbasis Quantum Teaching pada Pembelajaran Fisika di SMA". Respon peserta didik setelah melakukan kegiatan pembelajaran dengan menggunakan model quantum teaching juga baik yaitu peserta didik merasa senang belajar menggunakan model ini.
Berdasarkan uraian di atas, peneliti menduga model quantum learning memiliki pengaruh terhadap hasil belajar fisika peserta didik. Alasan tersebut yang mendorong peneliti untuk melakukan pengembangan perangkat pembelajaran model quantum learning. Perangkat ini nantinya diharapkan mampu menjadi alternatif pilihan dalam melaksanakan pembelajaran untuk meningkatkan hasil belajar fisika peserta didik.

\section{METODE PENELITIAN}

Penelitian ini menggunakan metode penelitian dan pengembangan atau Research and Development (RnD). Metode penelitian dan pengembangan adalah metode penelitian yang digunakan untuk menghasilkan produk tertentu, dan menguji keefektifan produk tersebut (Sugiyono, 2018). Penelitian ini terdiri atas 4 tahap utama yaitu: (1) Define (pendefinisian); (2) Desain (perancangan); (3) Develop (pengembangan); dan (4) Desseminate (penyebarluasan). Subjek penelitian pengembangan perangkat pembelajaran model quantum learning untuk meningkatkan hasil belajar fisika ini adalah 15 peserta didik kelas XI MIPA 1 SMAN 2 Mataram Tahun Ajaran 2020/2021. Penelitian ini dilakukan pada bulan September 2020. Pengambilan data penelitian dilakukan selama kurang lebih tiga minggu bertempat di SMAN 2 Mataram.

Instrumen penelitian terdiri atas lembar validasi dansoal tes. Lembar validasi diberikan kepada tim ahli dan guru untuk megetahui validitas silabus, RPP, LKPD, soal dan video pembelajaran. Soal berbantuan google form diberikan kepada peserta didik untuk mendapatkan data empirik yang nantinya dianalisis validitas dan reliabilitasnya. Soal pretest dan post-test untuk menganalisis peningkatan hasil belajar fisika peserta didik.

Teknik analisis data meliputi uji validititas perangkat yang dilakukan dengan melihat nilai Content Validity Ratio (CVR) dan Content Validity Index (CVI). Cara menghitung nilai CVR adalah dengan menggunakan persamaan:

$$
\text { CVR }=\frac{\mathrm{Ne}-\frac{\mathrm{N}}{2}}{\frac{\mathrm{N}}{2}} .
$$

\section{(Lawshe, 1975)}

Selanjutnya dihitung pula CVI yang merupakan indikasi validitas isi tes. CVI merupakan rata-rata dari nilai CVR dari semua item.

$$
\mathrm{CVI}=\frac{\text { jumlah seluruh CVR }}{\text { jumlah butir item }} \text {. }
$$

Kategori hasil perhitungan CVR dan $\mathrm{CVI}$ rentang hasil nilai CVR dan $\mathrm{CVI}$ adalah 
$-1<0<1$. Angka tersebut dikategorikan sebagai berikut:

$$
\begin{aligned}
& -1<x<0=\text { tidak baik } \\
& 0=\text { baik } \\
& 0<x<1=\text { sangat baik }
\end{aligned}
$$

Dengan $x$ adalah CVI.

(Lawshe, 1975)

Uji reliabilitas dilakukan dengan melihat nilai percentage agreement (PA) masing-masing produk. Percentage Agreement (PA) dapat dirumuskan:

$$
(\mathrm{PA})=\left(1-\frac{\mathrm{A}-\mathrm{B}}{\mathrm{A}+\mathrm{B}}\right) 100 \%
$$

Instrumen dikatakan reliabel jika nilai presentase kesepakatannya lebih atau sama dengan $75 \%$. Jika dihasilkan kurang dari $75 \%$, maka harus diuji untuk kejelasan dan persetujuan dari pengamat (Borich, 1994).

$$
\text { Soal juga diujivaliditas dan }
$$

reliabilitasnya secara empirik. Uji validitas dilakukan untuk mengetahui kualitas setiap item yang membangun soal. Sebuah item memiliki validitas tinggi jika skor pada item mempunyai kesejajaran dengan skor total (Sahidu, 2018). Peneliti menggunakan teknik product moment dari Pearson untuk mengetahui validitas item:

$$
r_{x y}=\frac{n \sum X Y-\left(\sum X\right)\left(\sum Y\right)}{\sqrt{\left\{n \sum X^{2}-\left(\sum X\right)^{2}\right\}\left\{n \sum Y^{2}-\left(\sum Y\right)^{2}\right\}}} \cdots
$$

Setelah diperoleh harga $r_{x y}$, selanjutnya dikonsultasikan ke tabel harga kritik $r$ produk momen sehingga dapat diketahui signifikan atau tidaknya korelasi tersebut. Pada penelitian ini, peneliti mengguanakan rumus Kuder dan Richardson yaitu K-R 21 sebagai berikut:

$$
r_{11}=\left(\frac{n}{n-1}\right)\left(1-\frac{M(n-M)}{n S^{2}}\right)
$$

Setelah diperoleh nilai reliabilitas secara keseluruhan, selanjutnya dikonsultasikan dengan tabel harga $\mathrm{r}$ product moment.

Uji efektivitas dilakukan dengan melihat peningkatan hasil belajar fisika peserta didik dengan menghitung nilai standar gain dari hasil pretest dan posttest. Standar Gain ditentukan dengan menggunakan persamaan berikut :

$$
\text { gain }\langle g\rangle=\frac{\bar{X}_{\text {sesudah }}-\bar{X}_{\text {sebelum }}}{\bar{X}_{\text {maks }}-\bar{X}_{\text {sebelum }}}
$$

Berdasarkan hasil yang diperoleh dengan menggunakan standar gain, dikelompokkan katagori berdasarkan Tabel 1 tentang interpretasi standar gain di bawah ini.

Tabel 1 Interpretasi Standar Gain

\begin{tabular}{cc}
\hline Nilai $\langle\mathrm{g}\rangle$ & Klasifikasi \\
\hline$\langle\mathrm{g}\rangle \geq 0,7$ & Tinggi \\
$0,7\rangle\langle\mathrm{g}\rangle \geq 0,3$ & Sedang \\
$\langle\mathrm{g}\rangle\langle 0,3$ & Rendah \\
\hline & (Hake, 1998).
\end{tabular}

\section{HASIL DAN PEMBAHASAN Hasil Penelitian}

Tahap Pendefinisian (Define)

Tahap pendefinisian (define) bertujuan untuk mendapat informasi mengenai keadaan peserta didik, permasalahan-permasalahan yang muncul ketka pembelajaran, metode pembelajaran yang digunakan oleh guru, media penunjang dan kajian kurikulum yang digunakan. Pada analisis awal, Guru mengalami gangguan jaringan ketika berlangsungnya pengajaran. Guru biasanya menggunakan aplikasi zoom, namun waktu yang disediakan terbatas. Metode yang digunakan dalam pengajaran daring adalah metode ceramah yang diperkuat dengan pemberian materi melalui whatsapp. Meskipun demikian, guru masih sulit memonitor peserta didik dalam mempelajari materi yang diberikan. Peserta didik merasa jenuh dan keterbatasan kuota menyebabkan beberapa peserta didik tidak dapat melaksanakan pembelajaran sebagaimana mestinya. Pada analisis tugas, kurikulum yang digunakan adalah kurikulum 2013 pada KD 3.10 dan 4.10 yang kemudian ditentukan indikator ketercapaian kompetensi. Pada analisis konsep, materi yang digunakan yaitu Gelombang Bunyi dan Gelombang Cahaya. Selanjutnya ditentukan spesifikasi tujuan pembelajaran.

\section{Tahap Perancangan (Design)}

Tahap perancangan (design) merupakan tahap merancang draft awal perangkat pembelajaran yang akan digunakan dalam pembelajaran materi Gelombang Bunyi dan Gelombang Cahaya. Draft yang dihasilkan berupa silabus, RPP, LKPD, soal, video pembelajaran dan angket self-efficacy.

\section{Tahap Pengembangan (Develop)}

Tahap pengembangan (develop) merupakan tahap untuk menghasilkan produk pengembangan yang dilakukan melalui beberapa langkah, dalam hal ini yaitu penilaian validator ahli, revisi produk dan uji coba terbatas pada 15 orang peserta didik. Berikut rangkuman hasil analisis validitas produk ditunjukkan pada Tabel 2 .

Tabel 2 Rangkuman Hasil Analisis

ValiditasProduk oleh Validator Ahli

\begin{tabular}{cccc}
\hline No & Perangkat & CVI & Kualitas \\
\hline 1 & Silabus & 0,93 & Sangat Baik \\
2 & RPP & 0.90 & Sangat Baik \\
3 & LKPD & 0,92 & Sangat Baik \\
4 & Soal & 0,89 & Sangat Baik \\
6 & Video & 0,84 & Sangat Baik \\
\hline
\end{tabular}

Reliabilitas dalam penelitian ini menggunakan metode Borich, yang dikenal dengan 
Percentage Agreement (PA) yaitu persentase kesepakatan antar penilai yang merupakan suatu persentase kesesuaian nilai antara penilai. Metode Borich ini digunakan untuk 2 validator sehingga analisisnya dilakukan dengan cara mengkombinasikan 2 validator, sehingga terdapat 15 kombinasi untuk pasangan validator. Nilai Percentage Agreement (PA) dari setiap perangkat diambil nilai rata-rata dari kombinasi validator. Reliabilitas produk yang dikembangkan dapat dilihat pada Tabel 3.

Tabel 3 Rangkuman Hasil Analisis Reliabilitas Produk oleh Validator Ahli

\begin{tabular}{cccc}
\hline No & Produk & $\begin{array}{c}\text { Rata- } \\
\text { Rata PA }\end{array}$ & Kategori \\
\hline 1 & Silabus & $92,43 \%$ & Reliabel \\
2 & RPP & $91,19 \%$ & Reliabel \\
3 & LKPD & $92,74 \%$ & Reliabel \\
4 & Soal & $93,98 \%$ & Reliabel \\
6 & Video & $89,11 \%$ & Reliabel \\
\hline
\end{tabular}

Berdasarkan hasil uji coba soal yang terdiri dari 20 soal pilihan ganda, diperoleh sebanyak 11 butir valid dan 9 butir tidak valid. Uji reliabilitas pada penelitian ini menggunakan persamaan KR-21. Adapun hasil uji reliabilitas soal yang diperoleh yaitu sebesar 0,487 sehingga soal dapat dikatakan reliabel.

Berdasarkan analisis yang telah dilakukan, diperoleh nilai standar gain secara keseluruhan sebesar 0,114. Dari hasil ini, berdasarkan interpretasi nilai standar gain maka peningkatan hasil belajar fisika subjek berada pada kategori rendah. Jika dilihat dari rata-rata pretest sebesar 38,33 dan posttest sebesar 47,67 , terjadi peningkatan hasil belajar fisika peserta didik. Adapun dibawah ini Tabel 4 ringkasan hasil analisis hasil belajar menggunakan standar gain.

Tabel 4 Ringkasan Hasil Analisis Peningkatan Hasil Belajar Fisika Menggunakan Standar

\begin{tabular}{cccc}
\multicolumn{4}{c}{ Gain } \\
\hline Nilai $\langle g\rangle$ & Klasifikasi & $\begin{array}{c}\text { Jumlah } \\
\text { Peserta } \\
\text { Didik }\end{array}$ & Presentase \\
\hline $\begin{array}{c}\langle\mathrm{g}>\geq 0,7 \\
0,7\end{array}$ & Tinggi & 0 & $0 \%$ \\
$\begin{array}{c}>\langle\mathrm{g}>\geq \\
0,3\end{array}$ & Sedang & 4 & $27 \%$ \\
$\langle\mathrm{~g}>\langle 0,3$ & Rendah & 11 & $73 \%$ \\
\hline
\end{tabular}

Rata-rata nilai pretest dan posttest peserta didik dapat dilihat pada Gambar 1 di bawah ini.

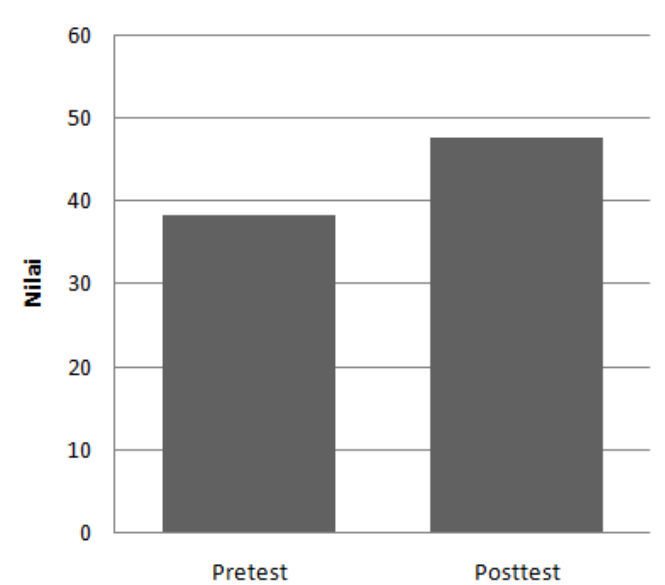

Gambar 1 Hasil Peningkatan Hasil Belajar Fisika

\section{Tahap Penyebarluasan (Disseminate)}

Tahap penyebarluasan (disseminate) merupakan tahap akhir dari tahap penelitian pengembangan ini. Tujuan dari tahap ini yaitu penyebarluasan produk penelitian. Adapun pelaksanaannya, yaitu artikel dari penelitian pengembangan ini dipublikasikan secara online dalam e-journal.

\section{Pembahasan}

Berdasarkan hasil analisis skor validasi ahli diperoleh CVI sebesar 0,93 sehingga silabus dinyatakan memiliki kualitas yang sangat baik. Reliabilitas silabus ditentukan berdasarkan nilai Percentage agreemant (PA) yang diperoleh. Rata-rata Percentage Agreement (PA) silabus mencapai $75 \%$, yaitu sebesar $92,43 \%$ sehingga dinyatakan reliabel. Hal tersebut berarti bahwa silabus berbasis model quantum learning valid dan reliabel sehingga layak digunakan sebagai pedoman dalam penyusunan RPP.

Berdasarkan hasil analisis skor validasi ahli diperoleh CVI sebesar 0,90 sehingga RPP dinyatakan memiliki kualitas yang sangat baik. Reliabilitas RPP ditentukan berdasarkan nilai Percentage agreemant (PA) yang diperoleh. Rata-rataPercentage Agreement (PA) RPP mencapai $75 \%$, yaitu sebesar $91,19 \%$ sehingga dinyatakan reliabel. Hal tersebut berarti bahwa RPP berbasis model quantum learning valid dan reliabel sehingga layak diterapkan dalam kegiatan pembelajaran.

Berdasarkan hasil analisis skor validasi ahli diperoleh $\mathrm{CVI}$ sebesar 0,92 sehingga LKPD dinyatakan memiliki kualitas yang sangat baik. Reliabilitas LKPD ditentukan berdasarkan nilai Percentage agreemant (PA) yang diperoleh. Rata-rata Percentage Agreement (PA) LKPD mencapai $75 \%$, yaitu sebesar $92,74 \%$ sehingga dinyatakan reliabel. Hal tersebut berarti bahwa LKPD berbasis model quantum learning valid dan reliabel sehingga layak diterapkan dalam 
kegiatan pembelajaran.

Berdasarkan hasil analisis skor validasi ahli diperoleh CVI sebesar 0,89 sehingga soal dinyatakan memiliki kualitas yang sangat baik. Reliabilitas soal ditentukan berdasarkan nilai Percentage agreemant (PA) yang diperoleh. Rata-rataPercentage Agreement (PA) soal mencapai $75 \%$, yaitu sebesar $93,98 \%$ sehingga dinyatakan reliabel. Soal juga diuji validitas dan reliabilitasnya secara empirik pada 27 orang peserta didik. Berdasarkan hasil uji coba empirik ini, dinyatakan 11 soal valid dan 9 soal tidak valid. Soal yang tidak valid selanjutnya direvisi sebelum digunakan untuk mengukur hasil belajar fisika peserta didik. Soal dinyatakan reliabel dengan nilai r-hitung yakni 0,487 lebih besar dari r-tabel yakni 0,444. Hal tersebut berarti bahwa soal dinyatakan layak digunakan untuk mengukur hasil belajar fisika peserta didik pada materi gelombang bunyi dan gelombang cahaya.

Berdasarkan hasil analisis skor validasi ahli diperoleh CVI sebesar 0,84 sehingga video dinyatakan memiliki kualitas yang sangat baik. Reliabilitas video pembelajaran ditentukan berdasarkan nilai Percentage agreemant (PA) yang diperoleh. Rata-rataPercentage Agreement (PA) video mencapai $75 \%$, yaitu sebesar $89,11 \%$ sehingga dinyatakan reliabel. Hal tersebut berarti bahwa videopembelajaran model quantum learning valid dan reliabel sehingga layak digunakan sebagai contoh penerapan pembelajaran dengan model quantum learning. Setelah dilaksanakannya penelitian, dihasilkan juga video pembelajaran daring yang menerapkan perangkat model quantum learning.

Adapun secara ringkas, dari 15 peserta didik terdapat 4 peserta didik pada kategori sedang dan sebanyak 11 peserta didik pada kategori rendah. Berdasarkan rata-rata pretest sebesar 38,33 dan posttest sebesar 47,67 untuk keseluruhan peserta didik, maka terjadi peningkatan hasil belajar fisika peserta didik pada materi pokok gelombang bunyi dan gelombang cahaya yang diajarkan menggunakan model quantum learning. Hal ini disebabkan karena dalam pembelajaran model quantum learning terjadi kebermaknaan pembelajaran. Pada tahap tumbuhkan, guru menumbuhkan motivasi belajar peserta didik menggunakan kekuatan AMBAK (Apa Manfaat Bagiku?). Peserta didik juga diberikan kesempatan untuk menghubungkan pengalaman hidupnya dengan manfaat dari materi yang diajarkan. Selain itu, peserta didik juga merasakan langsung pengalaman belajarnya melalui percobaan yang dilakukan sesuai dengan LKPD yang diterapkan. Guru tidak memberikan paksaan dan menciptakan suasana belajar yang nyaman. Guru juga memberi waktu untuk membaca LKPD dan mencatat materi yang dijelaskan agar peserta didik memiliki waktu untuk memaknai sejenak materi yang dipelajari. Rendahnya peningkatan hasil belajar fisika disebabkan oleh beberapa kendala dalam pelaksanaan kegiatan pembelajarannya, antara lain karena optimalnya interaksi antara peserta didik dengan guru maupun dengan temannya akibat pembelajaran daring, keterbatasan waktu pada aplikasi zoom yang digunakan pada pertemuan tiga dan empat menyebabkan pembelajaran berlanjut menggunakan aplikasi whatsapp sehingga tidak memungkinkan guru untuk mengontrol penuh jalannya proses pembelajaran.

\section{SIMPULAN DAN SARAN}

Berdasarkan hasil analisis data penelitian, maka diperoleh kesimpulan sebagai berikut:

Perangkat pembelajaran model quantum learning yang berupa silabus, RPP, LKPD dan video pembelajaran dikembangakan berdasarkan langkah-langkah pembelajaran model quantum learning. Dikembangkan juga soal tes yang disusun berdasarkan tujuan yang hendak dicapai dan berdasarkan tingkatan ranah kognitif yaitu $\mathrm{C} 1$ sampai $\mathrm{C} 6$.

Perangkat pembelajaran model quantum learning pada materi pokok Gelombang Bunyi dan Gelombang Cahaya yang meliputi silabus, RPP, LKPD, soal tes dan video pembelajaran yang dikembangkan memiliki kualitas sangat baik dan reliabel sehingga layak diterapkan dalam pembelajaran daring untuk meningkatkan hasil belajar fisika peserta didik.

Perangkat pembelajaran fisika berbasis model quantum learning pada materi pokok Gelombang Bunyi dan Gelombang Cahaya efektif digunakan untuk meningkatkan hasil belajar fisika peserta didik dalam pembelajaran daring. Hal ini dilihat dari hasil uji terbatas yang menunjukkan bahwa hasil belajar mengalami peningkatan dengan nilai standar gain sebesar 0,114 .

Berdasarkan keterbatasan penelitian terdapat beberapa saran untuk perbaikan penelitian pengembangan pada tahap lebih lanjut sebagai berikut:

Perangkat pembelajaran dengan menggunakan model quantum learning yang telah disusun dapat langsung digunakan oleh guru dalam pembelajaran fisika di kelas.

Sebelum menerapkan model quantum learning secara daring, guru sebaiknya mempersiapkan jaringan dan perangkat komputer yang mumpuni untuk meminimalisir gangguan ketika sedang mengajar. 
Guru yang menerapkan perangkat pembelajaran fisika berbasis model quantum learning sebaiknya benar-benar menguasai kelas dan memahami karkteristik setiap peserta didiknya.

Perlu dilakukan penelitian sejenis yang berkaitan dengan materi lain dengan menggunakan model quantum learning, tentunya dengan karakteristik peserta didik yang berbeda untuk memperoleh hasil yang lebih baik.

\section{DAFTAR RUJUKAN}

Afandi, M., Chamalah, E., \& Wardani, O. P. (2013). Model Dan Metode Pembelajaran Di Sekolah. Semarang: Unisulla Press.

Borich, G. D. (1994). Observation Skill for Effective Teaching. New York: Macmillan Publishing Company.

Doyan, A. (2015). Penerapan Model Pembelajaran Kuantum Pada Matakuliah. In Jurnal Pendidikan Fisika dan Teknologi,1(1), 1-8.

Gunawan, I., \& Paluti, A. R. (2017). Premiere Educandum. E-Journal.Unipma, 7(1), 1-8. http://ejournal.unipma.ac.id/index.php/PE

Hake, R. R. (1998). Interactive-engagement versus traditional methods: A sixthousand-student survey of mechanics test data for introductory physics courses. In American Journal of Physics,66(1)., 6474. https://doi.org/10.1119/1.18809

Hidayana, I., \& Juliani, R. (2014). Pengaruh Model Pembelajaran Quantum Teaching terhadap Hasil Belajar Siswa pada Materi Pokok Zat dan Wujudnya di Kelas VII Semester I SMP Negeri 3 Percut Sei Tuan T . P 2013 / 2014. Jurnal Inpafi, 2(2), 9199.

Kosasih, N., \& Sumarna, D. (2013). Pembelajaran Quantum dan Optimalisasi Kecerdasan. Bandung: Alfabeta.

LAWSHE, C. H. (1975). a Quantitative Approach To Content Validity. In Personnel Psychology, 28(4), 563-575.. https://doi.org/10.1111/j.17446570.1975.tb01393.x

Undang-Undang Republik Indonesia Nomor 20 Tahun 2003 Sistem Pendidikan Nasional. 8 Juli 2003. Lembaran Negara Republik Indonesia Tahun 2003 Nomor 4301. Jakarta.

Ningrum, A. P., Lesmono, A. D., Bachtiar, R. W. (2017). Pengembangan Bahan Ajar Berupa Modul Berbasis Quantum Teaching pada Pembelajaran Fisika di SMA. Jurnal Pembelajaran Fisika, 5(4), 315-320.

Rosa, F. O. (2015). Analisis Kemampuan Siswa Kelas X pada Ranah Kognitif , Afektif dan
Volume 7, Nomor 1, Mei 2021. p-ISSN : 2460-9587 e-ISSN : 2614-7017

Psikomotorik.Jurnal Fisika dan Pendidikan Fisika, 1(2), 24-28.

Rusyadi, A., Zainuddin, Z., \& Wati, M. (2013). Pengembangan Perangkat Pembelajaran Quantum Teaching Pada Materi Ajar Elastisitas. Berkala Ilmiah Pendidikan Fisika, 1(1), 82-90.. https://doi.org/10.20527/bipf.v1i1.864

Sahidu, H. (2018). Evaluasi Pembelajaran Fisika. Mataram: Penerbit Arga Puji Press.

Solikin, M., \& Abdullah, A. A. (2014). Pengaruh Quantum Teaching terhadap Hasil Belajar Siswa pada Pokok Bahasan Hukum Newton di Kelas X SMA Wahid Hasyim 4 Sidoarjo. Jurnal Inovasi Pendidikan Fisika (JIPF),03(02), 10-13.

Sugiyono. (2018). Metode Penelitian Pendidikan (Pendekatan Kuantitatif, Kualitatif, dan R\&D). Bandung: Alfabeta. 